\title{
Silver/graphene-modified Boron Doped Diamond Electrode for Selective Detection of Carbaryl and Paraquat from Water
}

\author{
Aniela Pop ${ }^{1}$, Sandra Lung ${ }^{1}$, Corina Orha ${ }^{2}$, Florica Manea ${ }^{1, *}$ \\ ${ }^{1}$ Department of Applied Chemistry and Engineering of Inorganic Compounds and Environment, \\ Politehnica University of Timisoara, Blv. Vasile Parvan No. 6, 300223, Timisoara, Romania, Tel.: +40 \\ 256403070 \\ ${ }^{2}$ National Condensed Matter Department, Institute for Research and Development in Electrochemistry \\ and Condensed Matter, Timisoara, 1 P. Andronescu Street, 300254 Timisoara, Romania \\ *E-mail: florica.manea@.upt.ro
}

doi: $10.20964 / 2018.03 .02$

Received: 12 September 2017 / Accepted: 14 November 2017 / Published: 5 February 2018

\begin{abstract}
A novel silver/graphene-modified boron doped diamond electrode (BDDGRAg) was obtained to determine selectively carbaryl and paraquat pesticides from aqueous solution, based on the electrochemical oxidation of carbaryl (CR) and the electrochemical reduction of paraquat (PQ). Compared with graphene-modified boron doped diamond electrode (BDDGR), BDDGRAg exhibited excellent electrocatalytic activity towards CR electrooxidation and PQ electroreduction. Simple and fast voltammetric methodology for selective CR and PQ detection was developed based on the selection of potential range corroborated with the optimum operating conditions of the differential pulse voltammetry technique (DPV) at BDDGRAg electrode. The lowest limit of detection of $1.14 \mathrm{nM}$ was determined for the selective detection of PQ within potential range of 0 to $-1 \mathrm{~V} / \mathrm{SCE}$ using DPV under step potential of $5 \mathrm{mV}$ and the modulation amplitude of $200 \mathrm{mV}$ without interference of CR presence. Also, the lowest limit of detection of $1.15 \mathrm{nM}$ was found for the selective detection of CR within the potential range of 0 to $+1.5 \mathrm{~V} / \mathrm{SCE}$ under the step potential of $6 \mathrm{mV}$ and the modulation amplitude of $800 \mathrm{mV}$. Proof-of-concept is demonstrated by the application in the real surface water sample.
\end{abstract}

Keywords: electrocatalytic activity; selective detection; pesticides; carbaryl; paraquat.

\section{FULL TEXT}

(C) 2018 The Authors. Published by ESG (www.electrochemsci.org). This article is an open access article distributed under the terms and conditions of the Creative Commons Attribution license (http://creativecommons.org/licenses/by/4.0/). 